\title{
Myocardial injury in hospitalized COVID-19 patients: a retrospective study, systematic review, and meta-analysis
}

\author{
Khalid Changal' ${ }^{1}$, Spiro Veria², Sean Mack², David Paternite², Shoaib Altaf Sheikh³ ${ }^{3}$ Mitra Patel ${ }^{2}$, Tanveer Mir ${ }^{4}$, \\ Mujeeb Sheikh ${ }^{*}$ and P. Kasi Ramanathan ${ }^{5}$
}

\begin{abstract}
Introduction: The majority of studies evaluating the effect of myocardial injury on the survival of COVID-19 patients have been performed outside of the United States (U.S.). These studies have often utilized definitions of myocardial injury that are not guideline-based and thus, not applicable to the U.S. patient population.

Methods: The current study is a two-part investigation of the effect of myocardial injury on the clinical outcome of patients hospitalized with COVID-19. The first part is a retrospective analysis of 268 patients admitted to our healthcare system in Toledo, Ohio, U.S.; the second part is a systematic review and meta-analysis of all similar studies performed within the U.S.

Results: In our retrospective analysis, patients with myocardial injury were older (mean age 73 vs. 59 years, $P$ 0.001), more likely to have hypertension ( $86 \%$ vs. $67 \%, P 0.005)$, underlying cardiovascular disease ( $57 \%$ vs. $24 \%, P 0.001)$, and chronic kidney disease ( $26 \%$ vs. $10 \%, P 0.004)$. Myocardial injury was also associated with a lower likelihood of discharge to home (35\% vs. 69\%, P 0.001), and a higher likelihood of death (33\% vs. 10\%, P 0.001), acute kidney injury ( $74 \%$ vs. $30 \%, P 0.001$ ), and circulatory shock (33\% vs. 12\%, P 0.001). Our meta-analysis included 12,577 patients from 8 U.S. states and 55 hospitals who were hospitalized with COVID-19, with the finding that myocardial injury was significantly associated with increased mortality (HR 2.43, Cl 2.28-3.6, P 0.0005). The prevalence of myocardial injury ranged from 9.2 to $51 \%$, with a mean prevalence of $27.2 \%$.
\end{abstract}

Conclusion: Hospitalized COVID-19 patients in the U.S. have a high prevalence of myocardial injury, which was associated with poorer survival and outcomes.

\section{Introduction}

The COVID-19 pandemic continues to affect millions of people in the United States (U.S.) and across the world [1]. Myocardial injury, as reflected by an increase in the serum troponin level above the 99th percentile, has been found to be relatively common in hospitalized COVID-19

\footnotetext{
*Correspondence: Smujeeb73@gmail.com

${ }^{5}$ Department of Cardiovascular Medicine, Interventional Cardiology,

Promedica Toledo Hospital, 2109 Hughes Dr, Jobst Tower 3rd Floor,

Toledo, OH 43606, USA

Full list of author information is available at the end of the article
}

patients and may predict a poor prognosis. However, most of these studies have been performed outside of the U.S. [2-4] and utilize definitions of myocardial injury that are not guideline-based, thus making it difficult to apply such findings to the hospitalized COVID-19 population within the U.S. [5-7]. The goal of the present study is to determine the prevalence of myocardial injury in the hospitalized COVID-19 patient population in the U.S., compare outcomes with hospitalized patients who have COVID-19 without myocardial injury, and to determine the risk factors for the development of myocardial injury 
and possible differences in clinical outcome between the two groups. In addition, we carry out a systematic review of current U.S. studies, summarize their findings, and perform a meta-analysis.

\section{Methods}

This study has two parts: one is a retrospective analysis of patients admitted to our health system; the second is a systematic review and meta-analysis of all similar studies performed in the U.S.

We conducted a retrospective study of a hospitalized patient population at two tertiary care hospitals in Toledo, Ohio, U.S. Adult ( $>18$ years) patients who were hospitalized with the diagnosis of COVID-19 from 1 January 2020 through 1 May 2020 were included. Patients with type $1,3,4$, and 5 myocardial infarctions were excluded from the study. Real-Time RT-PCR (cobas ${ }^{\circledR}$ SARS-CoV-2 Test) was used to establish COVID-19 diagnosis via nasopharyngeal and oropharyngeal swab samples obtained from our patients.

Myocardial injury was defined using the fourth universal definition of myocardial infarction as below:

Detection of a rise and/or fall of cTn with at least one value above the 99th percentile (in our laboratory this a troponin $\mathrm{I}>0.04 \mathrm{ng} / \mathrm{ml}$ ) and myocardial oxygen supply and demand mismatch not related to coronary thrombosis, with a minimum of one of the following: clinical symptoms related to cardiac ischemia; electrocardiographic changes suggestive of ischemia; new and pathological Q waves; imaging suggestive of acute loss of viable myocardium, or incident regional wall motion abnormalities consistent with ischemia [8].

All hospitalized COVID-19 patients received an EKG on admission. The present study only included patients who had serum troponin levels checked, which was based on clinical suspicion and/or EKG or imaging abnormalities. Eleven patients were excluded from the study as serum troponin was not measured in their cases.

Data were collected by review of individual electronic medical records from the hospital database. Data were collected on demographics, baseline comorbidities, hospital course, clinical and laboratory variables, cost, and outcomes. The underlying cardiovascular disease (CVD) status was identified by review of patient charts. To qualify for the CVD group, patients needed to have at least one of the following diagnoses: ischemic heart disease, congestive heart failure, and/or atrial fibrillation.

The statistics were performed using Statistical Package for the Social Sciences (SPSS), Version 20.0. We used mean, standard deviation/standard error of mean, and percentage when appropriate for the patient's characteristic description. Group differences were compared using the Pearson $\chi^{2}$ or Fisher's exact test for categorical variables, or the Student $t$ test for continuous variables. $P$ values $<0.05$ were regarded as significant. We conducted univariate and multivariate regression analysis for factors contributing to myocardial injury, and for the effect of myocardial injury on different outcomes. The variables with statistical significance on univariate analysis were analyzed with multivariate analysis. Multivariate analysis was performed separately for clinical factors (4 variables) and for hospital course/clinical outcomes (4 variables).

The Institutional Review Board of Promedica Health System in Toledo, Ohio, U.S. approved the current study.

Review and meta-analysis were performed using Preferred Reporting Items for Systematic Reviews and MetaAnalyses guidelines. The study methodology is described in the Additional file 1. We exclusively included studies performed in the U.S. We searched multiple databases using keywords such as "myocardial injury", "troponin", and "COVID-19". A systematic review was performed. Quantitative meta-analysis was performed only on studies that had clear outcomes defined. One study was excluded as it included only pregnant patients. We used hazard ratio (HR) and corresponding 95\% confidence interval (CI) for measuring mortality outcomes. Metaanalysis was performed using Review Manager Version 5.3 (The Nordic Cochrane Center, The Cochrane Collaboration, 2014), $\mathrm{R}$ version 3.6.2.

\section{Results}

A total of 268 patients were included in this study at our health system in Toledo, Ohio, U.S. Fifty-eight (22.4\%) patients met the inclusion criteria of myocardial injury, and 210 patients were included in the no myocardial injury group. Baseline characteristics are described in Table 1. Patients with myocardial injury were older (mean age 73 vs. 59 years, $P 0.001$ ), more likely to have hypertension ( $86 \%$ vs. $67 \%$, P 0.005$)$, underlying cardiovascular disease ( $57 \%$ vs. $24 \%, P 0.001)$, ischemic heart disease ( $35 \%$ vs. $16 \%, P 0.003)$, heart failure with reduced ejection fraction ( $12 \%$ vs. $3 \%, P 0.009)$, heart failure with preserved ejection fraction (19\% vs. $7 \%, P$ 0.012), atrial fibrillation $(21 \%$ vs. $7 \%, P$ 0.005), history of stroke $(28 \%$ vs. $8 \%, P 0.001)$, chronic kidney disease $(26 \%$ vs. $10 \%, P$ $0.004)$, and end-stage renal disease ( $12 \%$ vs. $2 \%, P$ 0.003). No significant statistical difference was noticed for sex, race, history of diabetes mellitus, active cancer, chronic liver disease, or home ACE inhibitor or Angiotensin II receptor blocker therapy. Patients in the myocardial injury group were less likely to initially present with fever ( $40 \%$ vs. $58 \%, P 0.022)$, dry cough ( $47 \%$ vs. $68 \%, P 0.005)$, or myalgias ( $9 \%$ vs. $27 \%, P$ 0.006). Serum troponins were measured in 97\% of patients hospitalized for COVID-19.

Table 2 describes the effect of myocardial injury on hospital course and clinical outcomes. Patients with 
Table 1 Patient characteristics and comorbidities; comparison of patients with and without myocardial injury

\begin{tabular}{|c|c|c|c|c|}
\hline Baseline characteristics & All patients $(\mathrm{N}=268)$ & Myocardial injury $(\mathrm{N}=58)$ & $\begin{array}{l}\text { No myocardial injury } \\
(\mathrm{N}=210)\end{array}$ & $P$ value \\
\hline Age & $62 \pm 17$ & $73 \pm 14$ & $59 \pm 17$ & $<0.001$ \\
\hline \multicolumn{5}{|l|}{ Sex } \\
\hline Male, n (\%) & $139(52)$ & $30(52)$ & $109(52)$ & \multirow[t]{2}{*}{1.000} \\
\hline Female, n (\%) & $129(48)$ & $28(48)$ & $101(48)$ & \\
\hline \multicolumn{5}{|l|}{ Race } \\
\hline Caucasian, n (\%) & $172(64)$ & $43(74)$ & $129(62)$ & \multirow[t]{4}{*}{0.176} \\
\hline African-American, n (\%) & $80(30)$ & $13(22)$ & $67(32)$ & \\
\hline Latino, n (\%) & $13(5)$ & $1(1)$ & $12(6)$ & \\
\hline Other, n (\%) & $2(1)$ & $1(1)$ & $1(1)$ & \\
\hline Hypertension, n (\%) & $191(71)$ & $50(86)$ & $141(67)$ & 0.005 \\
\hline Diabetes mellitus, n (\%) & $97(36)$ & $24(41)$ & $73(35)$ & 0.359 \\
\hline Cardiovascular disease, n (\%) & $84(31)$ & $33(57)$ & $51(24)$ & $<0.001$ \\
\hline Ischemic heart disease, n (\%) & $53(20)$ & $20(35)$ & $33(16)$ & 0.003 \\
\hline HFrEF, n (\%) & $13(5)$ & $7(12)$ & $6(3)$ & 0.009 \\
\hline HFpEF, n (\%) & $26(10)$ & $11(19)$ & $15(7)$ & 0.012 \\
\hline Atrial fibrillation, n (\%) & $27(10)$ & $12(21)$ & $15(7)$ & 0.005 \\
\hline Active cancer, n (\%) & $11(4)$ & $1(2)$ & $10(5)$ & 0.466 \\
\hline Stroke, n (\%) & $33(12)$ & $16(28)$ & $17(8)$ & $<0.001$ \\
\hline Chronic kidney disease, n (\%) & $36(13)$ & $15(26)$ & $21(10)$ & 0.004 \\
\hline ESRD on $\mathrm{HD}, \mathrm{n}(\%)$ & $11(4)$ & $7(12)$ & $4(2)$ & 0.003 \\
\hline Chronic liver disease, n (\%) & $13(5)$ & $3(5)$ & $10(5)$ & 1.000 \\
\hline Immunosuppressive state, n (\%) & $17(6)$ & $7(12)$ & $10(5)$ & 0.064 \\
\hline Home med: ACEi, n (\%) & $60(23)$ & $15(26)$ & $45(22)$ & 0.297 \\
\hline Home med: ARBs/ARNI, n (\%) & $31(12)$ & $5(9)$ & $26(12)$ & 0.496 \\
\hline \multicolumn{5}{|l|}{ Presenting vital signs } \\
\hline Heart rate & $93 \pm 19$ & $92 \pm 23$ & $93 \pm 17$ & 0.686 \\
\hline Respiratory rate & $22 \pm 6$ & $24 \pm 8$ & $22 \pm 6$ & 0.104 \\
\hline Systolic blood pressure & $127 \pm 21$ & $123 \pm 22$ & $128 \pm 21$ & 0.158 \\
\hline \multicolumn{5}{|l|}{ Reasons for hospitalization } \\
\hline Chest pain, $\mathrm{n}(\%)$ & $49(18)$ & $7(12)$ & $42(20)$ & 0.185 \\
\hline Palpitations, n (\%) & $4(2)$ & $2(4)$ & $2(1)$ & 0.192 \\
\hline Fever, n (\%) & $142(54)$ & $22(40)$ & $120(58)$ & 0.022 \\
\hline Malaise, n (\%) & $120(46)$ & $21(38)$ & $99(48)$ & 0.224 \\
\hline Dry Cough, n (\%) & $167(64)$ & $26(47)$ & $141(68)$ & 0.005 \\
\hline Anorexia, n (\%) & $39(15)$ & $4(7)$ & $35(17)$ & 0.089 \\
\hline Myalgia, n (\%) & $60(23)$ & $5(9)$ & $55(27)$ & 0.006 \\
\hline Dyspnea, n (\%) & $215(82)$ & $44(80)$ & $171(83)$ & 0.690 \\
\hline Orthopnea, n (\%) & $1(0.4)$ & $0(0)$ & $1(0.5)$ & 1.000 \\
\hline Expectoration, n (\%) & $24(9)$ & $4(7)$ & $20(10)$ & 0.794 \\
\hline Diarrhea, n (\%) & $66(25)$ & $8(15)$ & $58(28)$ & 0.054 \\
\hline Headache, n (\%) & $40(15)$ & $4(7)$ & $36(18)$ & 0.090 \\
\hline Vomiting, n (\%) & $37(14)$ & $6(11)$ & $31(15)$ & 0.519 \\
\hline Abdominal pain, $\mathrm{n}(\%)$ & $23(9)$ & $6(11)$ & $17(8)$ & 0.592 \\
\hline
\end{tabular}

$\mathrm{HFpEF}$ congestive heart failure with preserved ejection fraction, $\mathrm{EF}<40 \%, \mathrm{HFrEF}$ congestive heart failure with reduced ejection fraction, $\mathrm{EF}>50 \%$. There were 3 patients with $\mathrm{HfmrEF}(\mathrm{EF} 40-50 \%)$ and were included in HfrEF group. ESRD on HD=End stage renal disease on hemodialysis. Immunosuppressive state anyone on chronic immunomodulatory drugs or with immunodeficiencies such as HIV, ARNI angiotensin receptor-neprilysin inhibitor, EKG electrocardiogram 
Table 2 Patient outcomes and laboratory studies during hospitalization, and comparison of patients with and without myocardial injury

\begin{tabular}{|c|c|c|c|c|}
\hline Clinical course/outcome & All patients $(\mathrm{N}=268)$ & Myocardial injury ( $\mathrm{N}=58$ ) & $\begin{array}{l}\text { No myocardial injury } \\
(\mathrm{N}=210)\end{array}$ & $P$ value \\
\hline Longest QTc measurement (ms) & $446 \pm 37$ & $457 \pm 37$ & $443 \pm 36$ & 0.008 \\
\hline Cardiac arrest, $\mathrm{n}(\%)$ & $1(0.4)$ & 0 & $1(0.5)$ & 1.000 \\
\hline \multicolumn{5}{|l|}{ EKG and cardiac rhythm abnormalities } \\
\hline Arrhythmia, n (\%) & $30(11)$ & $16(28)$ & $14(7)$ & $<0.001$ \\
\hline Atrial fibrillation, $\mathrm{n}(\%)$ & $24(9)$ & $11(19)$ & $13(6)$ & 0.007 \\
\hline Sustained VT, n (\%) & $3(1)$ & $2(3)$ & $1(0.5)$ & 0.119 \\
\hline VT, n (\%) & $4(1.5)$ & $2(3)$ & $2(1)$ & 0.205 \\
\hline 1st degree heart block, n (\%) & $6(2)$ & $2(3)$ & $4(2)$ & 0.613 \\
\hline 2nd (Type 2) or 3rd degree heart block, n (\%) & $2(1)$ & $0(0)$ & $2(1)$ & 1.000 \\
\hline New left or right bundle branch block, n (\%) & $23(9)$ & $4(7)$ & $19(9)$ & 0.793 \\
\hline ST depression or T wave inversion, $\mathrm{n}(\%)$ & $36(14)$ & $13(22)$ & $23(11)$ & 0.031 \\
\hline ST elevation, n (\%) & $5(2)$ & $3(5)$ & $2(1)$ & 0.069 \\
\hline QT prolongation & $66(25)$ & $21(36)$ & $45(21)$ & 0.025 \\
\hline Abnormal EKG, n (\%) & $99(37)$ & $35(60)$ & $64(30)$ & $<0.001$ \\
\hline Any arrhythmia, n (\%) & $39(15)$ & $17(29)$ & $22(11)$ & 0.001 \\
\hline Troponin I peak (ng/mL) & $0.34 \pm 1.50$ & $1.48 \pm 2.97$ & $0.02 \pm 0.02$ & $<0.001$ \\
\hline Abnormal BNP, n (\%) & $45(30)$ & $22(56)$ & $23(21)$ & $<0.001$ \\
\hline BNP peak (pg/mL) & $185 \pm 299$ & $373 \pm 411$ & $189 \pm 22$ & $<0.001$ \\
\hline High d-dimer, n (\%) & $184(72)$ & $47(84)$ & $137(69)$ & 0.028 \\
\hline D-dimer peak (ng/mL) & $3254 \pm 8868$ & $5854 \pm 12,899$ & $2640 \pm 7482$ & 0.022 \\
\hline Acute kidney injury, n (\%) & $107(40)$ & $43(74)$ & $64(30)$ & $<0.001$ \\
\hline Peak creatinine (mg/dL) & $1.85 \pm 2.15$ & $3.10 \pm 3.46$ & $1.51 \pm 1.49$ & $<0.001$ \\
\hline New HD or CVVHD, n (\%) & $6(2)$ & $1(2)$ & $5(2)$ & 1.000 \\
\hline Invasive ventilation, n (\%) & $50(19)$ & $13(22)$ & $37(18)$ & 0.447 \\
\hline Shock of any type, n (\%) & $44(16)$ & $19(33)$ & $25(12)$ & $<0.001$ \\
\hline ARDS, n (\%) & $41(15)$ & $11(19)$ & $30(14)$ & 0.407 \\
\hline Ischemic Stroke, n (\%) & $2(1)$ & $1(2)$ & $1(0.5)$ & 0.382 \\
\hline DVT and/or PE, n (\%) & $10(4)$ & $4(7)$ & $6(3)$ & 0.228 \\
\hline Death, n (\%) & $41(15)$ & $19(33)$ & $22(10)$ & $<0.001$ \\
\hline \multicolumn{5}{|l|}{ Discharge } \\
\hline Home, n (\%) & $165(62)$ & $20(35)$ & $145(69)$ & $<0.001$ \\
\hline SNF, n (\%) & $59(22)$ & $17(29)$ & $42(20)$ & \\
\hline LOS (days) & $9 \pm 9$ & $9 \pm 10$ & $9 \pm 9$ & 0.866 \\
\hline Cost of hospitalization (US dollars) & $92,727 \pm 125,821$ & $84,271 \pm 104,119$ & $95,535 \pm 131,126$ & 0.547 \\
\hline \multicolumn{5}{|l|}{ In hospital medications } \\
\hline Hydroxychloroquine, n (\%) & $187(70)$ & $37(65)$ & $150(72)$ & 0.329 \\
\hline Azithromycin, n (\%) & $40(15)$ & $10(18)$ & $30(14)$ & 0.536 \\
\hline Hydroxychloroquine AND Azithromycin, n (\%) & $33(12)$ & $8(14)$ & $25(12)$ & 0.654 \\
\hline Tocilizumab, n (\%) & $6(2)$ & $0(0)$ & $6(3)$ & 0.346 \\
\hline >1 QT prolonging drug, n (\%) & $139(52)$ & $30(53)$ & $109(52)$ & 1.000 \\
\hline Therapeutic anticoagulation, n (\%) & $23(9)$ & $10(18)$ & $13(6)$ & 0.025 \\
\hline Steroids, n (\%) & $41(15)$ & $18(32)$ & $23(11)$ & $<0.001$ \\
\hline ACEi/ARNI, n (\%) & $40(15)$ & $5(9)$ & $35(17)$ & 0.149 \\
\hline ARBs, n (\%) & $31(12)$ & $2(3)$ & $29(14)$ & 0.035 \\
\hline
\end{tabular}

Abnormal D-dimer was defined by more than the lab specified value of $255 \mathrm{ng} / \mathrm{mL}$. High troponin was defined by a value more than the lab specified value of $0.04 \mathrm{ng} /$ $\mathrm{mL}$. QTc was considered prolonged if more than $460 \mathrm{~ms}$ in men and more than $480 \mathrm{~ms}$ in women on any EKG done during hospital stay

Sl units for $B N P=p g / m L$ Abnormal BNP was defined by a value of more than $100 \mathrm{pg} / \mathrm{mL}$

Units for creatinine $=\mathrm{mg} / \mathrm{dL}$

Sl units for troponin $\mathrm{I}=\mathrm{ng} / \mathrm{mL}$ 
Table 2 (continued)

$A M A$ against medical advice, $A R N I$ angiotensin receptor-neprilysin inhibitor, $V T$ ventricular tachycardia, $A R D S$ acuterespiratory distress syndrome, $P E$ pulmonary embolism, HD hemodialysis, CVVD continuous venovenous hemodialysis, SNF skilled nursing facility, LOS length of stay

myocardial injury were more likely to have QT prolongation ( $36 \%$ vs. $21 \%, P$ 0.025), with longer QTc measurements (457 ms vs. $443 \mathrm{~ms}, P$ 0.008), and abnormal EKG readings $(60 \%$ vs. $30 \%, P$ 0.001), with greater likelihood of having arrhythmias (28\% vs. $7 \%, P 0.001)$, atrial fibrillation (19\% vs. $6 \%, P$ 0.007), ST depression or $\mathrm{T}$ wave inversion ( $22 \%$ vs. $11 \%, P$ 0.031). Patients with myocardial injury were also more likely to have abnormal BNP (56\% vs. $23 \%, P 0.001)$, elevated D-dimer $(84 \%$ vs. $69 \%, P$ 0.028 ) with higher D-dimer peak ( 5854 vs. $2640, P 0.022$ ), acute kidney injury $(74 \%$ vs. $30 \%, P 0.001)$, and circulatory shock (33\% vs. $12 \%, P$ 0.001). Patients with myocardial injury had a lower likelihood of discharge to home (35\% vs. $69 \%, P$ 0.001) and a higher likelihood of death (33\% vs. $10 \%, P 0.001)$. Patients with myocardial injury were more likely to have received therapeutic anticoagulation ( $18 \%$ vs. $6 \%, P 0.025)$, steroid therapy ( $32 \%$ vs. $11 \%$, $P$ 0.001), and less likely to have received angiotensin II receptor blocker therapy during their hospital course $(3 \%$ vs. $14 \%, P 0.035)$. There was no association between myocardial injury and length of stay or cost of hospitalization.

Univariate and Multivariate regression analysis were performed as detailed in Table 3. On univariate analysis, the odds of having myocardial injury were higher with age (OR 1.06, 95\% CI 1.04-1.08), hypertension (OR 3.06, 95\% CI 1.37-6.81), underlying cardiovascular disease (OR 4.12, 95\% CI 2.24-7.56), ischemic heart disease (OR 2.82, 95\% CI 1.46-5.44), congestive heart failure with reduced ejection fraction (OR 4.67, 95\% CI 1.50-14.49), congestive heart failure with preserved ejection fraction (OR 3.04, 95\% CI 1.31-7.05), atrial fibrillation (OR 3.39, 95\% CI 1.49-7.73), and end stage renal disease (OR 7.07, 95\% CI 1.99-25.07). The odds of having myocardial injury were also higher with abnormal EKG (OR 3.47, 95\% CI 1.90-6.34), and EKG findings of arrhythmia (OR 5.46, 95\% CI 2.47-12.07), atrial fibrillation (OR 3.53, 95\% CI 1.49-8.37), ST depression or T wave inversion (OR 2.34, 95\% CI 1.09-4.97), and QT prolongation (OR $2.08,95 \%$ CI 1.11-3.90). Additionally, the odds of having myocardial injury were also higher with abnormal BNP (OR 4.95, 95\% CI 2.27-10.82), high D-dimer (OR 2.40, 95\% CI 1.11-5.20), acute kidney injury (OR 3.39, 95\% CI 3.39-12.62), shock of any type (OR 3.70, 95\% CI 1.857.39), do not resuscitate \& comfort care status (OR 4.66, 95\% CI 2.49-8.71), discharge to skilled nursing facility (OR 2.94, 95\% CI 1.41-6.10), and death (OR 4.25, 95\% CI 2.09-8.61). On multivariate analysis, the association of myocardial injury with age, underlying cardiovascular disease, end stage renal disease, arrhythmia on EKG, abnormal BNP, and acute kidney injury was confirmed.

\section{Systematic review and meta-analysis}

Including the current study, a total of 7 studies were included in the review (Table 4) [8-13]. Six studies were included in quantitative analysis. All studies were retrospective in design and included only hospitalized COVID-19 patients within the U.S. The study by Pachtman et al. [13] was excluded as it included only pregnant patients. The quantitative analysis included data from 8 states or 55 hospitals. 12,577 patients were included in the quantitative analysis. The prevalence of myocardial injury ranged from 9.2 to $51 \%$. The overall mean prevalence of myocardial injury was $27.2 \%$. All studies included hospitalized patients.

In the meta-analysis, we found the presence of myocardial injury was significantly associated with mortality (HR 2.43, CI 2.28-3.6, P 0.0005, Fig. 1). Each study found an increased risk of mortality with myocardial injury.

\section{Discussion}

This study and review show myocardial injury is common (9-52\%) in hospitalized COVID-19 patients in the U.S. [9-14]. This is in contrast to studies from China, which show relatively lower (7-28\%) rates of myocardial injury in hospitalized COVID-19 patients [15-18]. We also found that development of myocardial injury in COVID19 U.S. patients is associated with increased mortality, change of code status to "do not resuscitate", discharge to skilled nursing facilities instead of home, development of acute kidney injury, circulatory shock, and arrhythmias.

We have, for the first time, shown in a meta-analysis on studies performed in the U.S. that myocardial injury significantly increases the mortality among hospitalized COVID-19 patients. This provides a high level of evidence. Similar to our results, a report of 416 patients from Wuhan, China demonstrated an HR of 3.41 (95\% CI 1.62-7.16) for death in patients with myocardial injury compared with patients without myocardial injury [15]. Of note, Nuzzi $V$ et al. found that in-hospital troponin elevation in Caucasian patients without myocardial injury at admission has a strong correlation with mortality [19]. We recommend that all patients admitted with COVID-19 should have troponin levels checked during their hospitalization. This, along with other clinical and laboratory variables, can provide further guidance on management and prognosis. The association of troponin elevation with increased mortality likely has two 
Table 3 Univariate and multivariate analysis for factors associated with myocardial injury

\begin{tabular}{|c|c|c|c|c|c|c|}
\hline \multirow[t]{2}{*}{ Clinical factors } & \multicolumn{3}{|c|}{ Univariate analysis } & \multicolumn{3}{|c|}{ Multivariate analysis } \\
\hline & Odds ratio & $\begin{array}{l}95 \% \text { confidence } \\
\text { interval }\end{array}$ & $P$ value & Odds ratio & $\begin{array}{l}95 \% \text { confidence } \\
\text { interval }\end{array}$ & $P$ value \\
\hline Age (years) & 1.06 & $1.04-1.08$ & $<0.001$ & 1.05 & $1.02-1.1$ & 0.00 \\
\hline Sex & 1.01 & $0.56-1.80$ & 0.981 & - & - & - \\
\hline Hypertension & 3.06 & $1.37-6.81$ & 0.006 & 1.37 & $0.56-3.36$ & 0.48 \\
\hline Diabetes mellitus & 1.33 & $0.73-2.40$ & 0.354 & - & - & - \\
\hline Cardiovascular disease & 4.12 & $2.24-7.56$ & $<0.001$ & 2.0 & $1.1-4.0$ & 0.04 \\
\hline Ischemic heart disease & 2.82 & $1.46-5.44$ & 0.002 & - & - & - \\
\hline HFrEF & 4.67 & $1.50-14.49$ & 0.008 & - & - & - \\
\hline HFpEF & 3.04 & $1.31-7.05$ & 0.009 & - & - & - \\
\hline Atrial fibrillation & 3.39 & $1.49-7.73$ & 0.004 & - & - & - \\
\hline ESRD on HD & 7.07 & $1.99-25.07$ & 0.002 & 6.62 & $1.7-25$ & 0.06 \\
\hline \multicolumn{7}{|l|}{ Hospital course and clinical outcome } \\
\hline \multicolumn{7}{|l|}{ EKG findings } \\
\hline Arrhythmia & 5.46 & $2.47-12.07$ & $<0.001$ & 3.04 & $1.1-9.3$ & 0.04 \\
\hline Atrial fibrillation & 3.53 & $1.49-8.37$ & 0.004 & - & - & - \\
\hline 1st degree heartblock & 1.84 & $0.33-10.30$ & 0.488 & - & - & - \\
\hline New BBB & 0.75 & $0.24-2.28$ & 0.606 & - & - & - \\
\hline ST depression or T wave inversion & 2.34 & $1.09-4.97$ & 0.027 & - & - & - \\
\hline QT prolongation & 2.08 & $1.11-3.90$ & 0.022 & - & - & - \\
\hline Abnormal EKG & 3.47 & $1.90-6.34$ & $<0.001$ & - & - & - \\
\hline Abnormal BNP & 4.95 & $2.27-10.82$ & $<0.001$ & 3.03 & $1.3-7.2$ & 0.01 \\
\hline High d-dimer & 2.40 & $1.11-5.20$ & 0.026 & 1.2 & $0.4-3.5$ & 0.73 \\
\hline Acute kidney injury & 6.54 & $3.39-12.62$ & $<0.001$ & 4.5 & $1.8-11$ & 0.001 \\
\hline Invasive ventilation & 1.35 & $0.66-2.75$ & 0.408 & - & - & - \\
\hline Shock of any type & 3.70 & $1.85-7.39$ & $<0.001$ & - & - & - \\
\hline ARDS & 1.44 & $0.67-3.08$ & 0.354 & - & - & - \\
\hline Ischemic stroke & 3.73 & $0.23-60.61$ & 0.354 & - & - & - \\
\hline Length of stay & 0.99 & $0.96-1.03$ & 0.865 & - & - & - \\
\hline Do not resuscitate and Comfort care & 4.66 & $2.49-8.71$ & $<0.001$ & - & - & - \\
\hline Discharge to skilled Nursing facility & 2.94 & $1.41-6.10$ & 0.004 & - & - & - \\
\hline Death & 4.25 & $2.09-8.61$ & $<0.001$ & - & - & - \\
\hline \multicolumn{7}{|l|}{ In hospital medications } \\
\hline Hydroxychloroquine & 0.73 & $0.39-1.36$ & 0.316 & - & - & - \\
\hline Anticoagulation & 1.76 & $1.01-3.06$ & 0.046 & - & - & - \\
\hline ACEi/ARNi & 0.47 & $0.18-1.27$ & 0.14 & - & - & - \\
\hline Steroids & 3.73 & $1.84-7.57$ & $<0.001$ & - & - & - \\
\hline
\end{tabular}

$H F P E F$ congestive heart failure with preserved ejection fraction, $H F r E F$ congestive heart failure with reduced ejection, $A R N I$ angiotensin receptor-neprilysin inhibitor, ESRD on HD End stage renal disease on hemodialysis, $B B B$ bundle branch block (complete left or right). OR for continuous variables is calculated for 1-unit increments

main reasons. Firstly, troponin elevation in COVID-19 is more likely to occur in patients with underlying cardiac and non-cardiac comorbidities, placing them at an increased risk of poor outcomes. Secondly, cardiac injury in the setting of COVID-19 is a marker of tissue hypoxia, myocardial cytotoxicity, systemic cytokine upregulation, demand-supply mismatch, thrombosis, and plaque vulnerability [20-22]. All of these processes suggest advanced disease and poor prognosis.
The underlying factors that predispose to the development of myocardial injury are age, hypertension, underlying CVDs, and chronic kidney disease. The CVDs associated with the development of myocardial injury are ischemic heart disease, heart failure (both preserved and reduced EF), and atrial fibrillation. Our review of other U.S. studies suggests similar risk factors for developing myocardial injury [9-14]. 


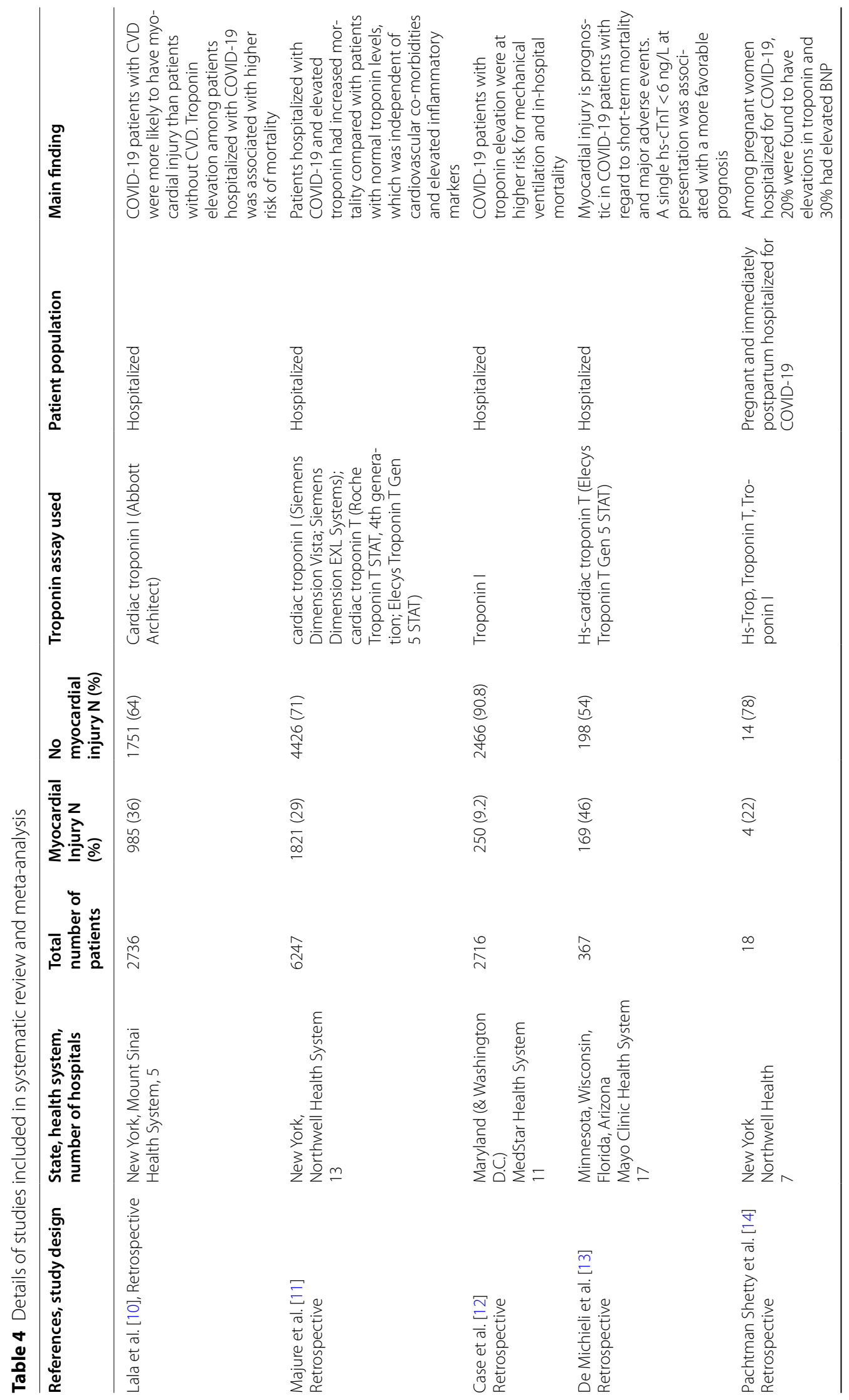




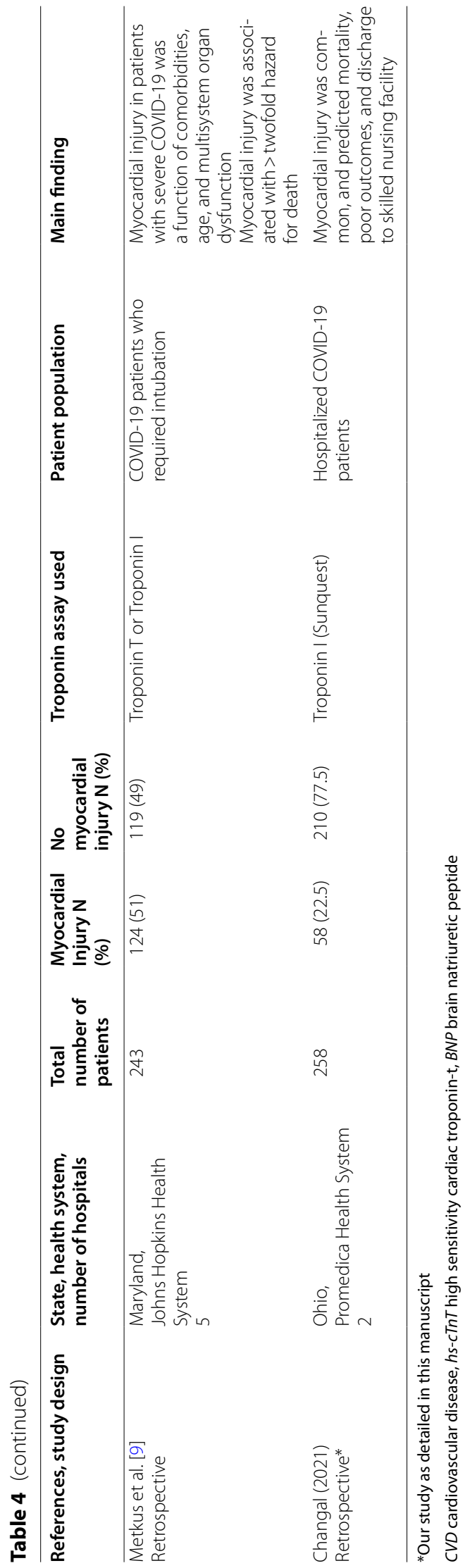




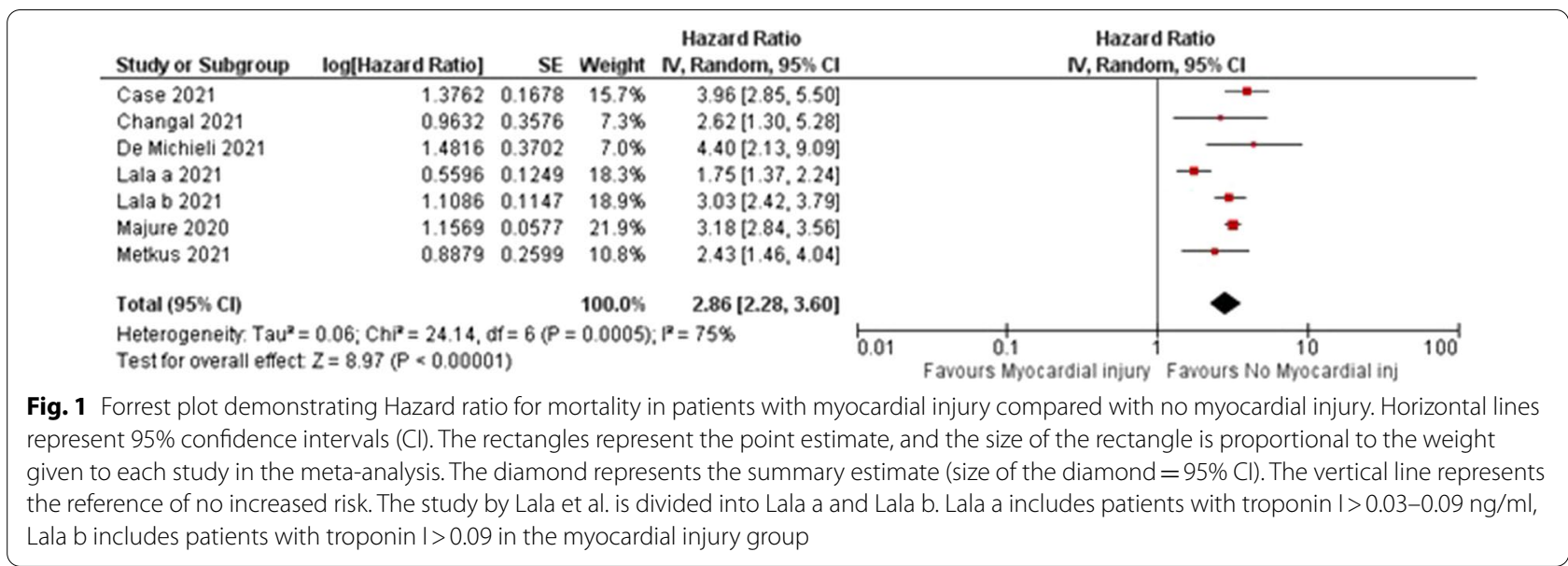

While some studies performed outside of the U.S. have investigated the association of myocardial injury with COVID-19, such studies have often used nonguideline definitions that utilize imaging and electrocardiographic abnormalities for establishing diagnosis. This increases the margin of error in diagnosing the patients with true myocardial injury, making such studies less reliable. We utilized a uniform and validated definition for Type $2 \mathrm{MI}$ in an attempt to avoid this error.

Although the patients with myocardial injury had poor outcomes, there was no significant difference in the healthcare costs. This is because many patients in the myocardial injury group were discharged to skilled nursing facilities rather than home, and likely would result in a higher overall cost. No other study in the review has studied the healthcare costs outcome.

There are some limitations to our study. All findings are retrospective in design and are thus limited by this. Another limitation is that only patients who had troponin levels checked during their hospitalization were included. However, only a small number of patients were excluded for lack of serum troponin testing $(n=11)$. All of the studies included patients prior to when vaccination against COVID-19 was available. Additionally, none of the included studies have provided data on coronary angiography in the included patients. Nevertheless, on this final point, diagnosis of myocardial injury is based on clinical, EKG, laboratory, and imaging data and coronary angiography is often not required to make this diagnosis. While some authors [23] have suggested a racial predisposition to adverse outcomes from COVID-19, the present study could not study the effect of race on mortality outcomes due to sample size limitations. Such data was also not available for meta-analysis.

To conclude, myocardial injury is a common phenomenon in hospitalized COVID-19 patients in the U.S. Elevated troponin in this population predicts a poor outcome and higher risk of mortality.

\section{Abbreviations}

ACEi: ACE inhibitor; ARBs: Angiotensin II receptor blocker; ARNI: Angiotensin receptor-neprilysin inhibitor; BBB: Bundle branch block (complete left or right); BNP: Brain natriuretic peptide; CVD: Cardiovascular disease; CVVHD: Continuous venovenous hemodialysis; ESRD: End stage renal disease; HD: Hemodialysis; HFpEF: Heart failure with preserved ejection fraction; HFrEF: Heart failure with reduced ejection fraction; hs-cTnT: High sensitivity cardiac troponin-t; LOS: Length of stay; SNF: Skilled nursing facility; SPSS: Statistical package for the social sciences; U.S.: United States; VT: Ventricular tachycardia.

\section{Supplementary Information}

The online version contains supplementary material available at https://doi. org/10.1186/s12872-021-02450-3.

Additional file 1. Search strategy and PRISMA checklist for the Meta-analysis.

\section{Acknowledgements}

None.

\section{Authors' contributions}

KC: Conceptualization; Data curation; Formal analysis; Investigation; Methodology; Project administration; Software; Writing—original draft; Writing-review and editing. SV, SM, DP, MP: Data collection, data review, Writing_-review and editing. SAS, TM: Data curation; Writing — review and editing. MS, MD and PKR: Conceptualization; Project administration; Resources; Writing —review and editing, Senior Authors. All authors have read and approved the manuscript.

\section{Funding}

None.

\section{Availability of data and materials}

Will be provided upon reasonable request. Please email Mujeeb A. Sheikh MD (smujeeb73@gmail.com) for requests. 


\section{Declarations}

Ethics approval and consent to participate

Institutional Review Board of Promedica Health System in Toledo, Ohio, USA approved the study. Individual consents from patients were not required as hospital registry was used, and data was de-identified. The study protocol was carried out in accordance with the Declaration of Helsinki.

\section{Consent for publication}

Not applicable.

\section{Competing interests}

The authors declared that they have no competing interest.

\section{Author details}

${ }^{1}$ Cardiovascular Medicine, University of Toledo, Toledo, OH, USA. ${ }^{2}$ Department of Medicine, University of Toledo College of Medicine and Life Sciences, Toledo, OH, USA. Internal Medicine, Nazareth Hospital (Trinity Health), Philadelphia, PA, USA. ${ }^{4}$ Internal Medicine, Detroit Medical Center, Wayne State University, Detroit, MI, USA. ${ }^{5}$ Department of Cardiovascular Medicine, Interventional Cardiology, Promedica Toledo Hospital, 2109 Hughes Dr, Jobst Tower 3rd Floor, Toledo, OH 43606, USA

Received: 19 August 2021 Accepted: 28 December 2021 Published online: 31 December 2021

\section{References}

1. Wei EK, Long T, Katz MH. Nine lessons learned from the COVID-19 pandemic for improving hospital care and health care delivery. JAMA Intern Med. 2021. https://doi.org/10.1001/jamainternmed.2021.4237.

2. Shi S, Qin M, Cai Y, Liu T, Shen B, Yang F, et al. Characteristics and clinical significance of myocardial injury in patients with severe coronavirus disease 2019. Eur Heart J. 2020;41:2070-9.

3. Guo T, Fan Y, Chen M, Wu X, Zhang L, He T, et al. Cardiovascular implications of fatal outcomes of patients with coronavirus disease 2019 (COVID19). JAMA Cardiol. 2020;5:811-8.

4. Lombardi CM, Carubelli V, lorio A, Inciardi RM, Bellasi A, Canale C, et al. Association of troponin levels with mortality in Italian patients hospitalized with coronavirus disease 2019: results of a multicenter study. JAMA Cardiol. 2020;5:1274-80.

5. Zhou F, Yu T, Du R, Fan G, Liu Y, Liu Z, et al. Clinical course and risk factors for mortality of adult inpatients with COVID-19 in Wuhan, China: a retrospective cohort study. Lancet. 2020;395:1054-62.

6. Huang C, Wang Y, Li X, Ren L, Zhao J, Hu Y, et al. Clinical features of patients infected with 2019 novel coronavirus in Wuhan, China. Lancet. 2020:395:497-506.

7. Wang D, Hu B, Hu C, Zhu F, Liu X, Zhang J, et al. Clinical characteristics of 138 hospitalized patients with 2019 novel coronavirus-infected pneumonia in Wuhan, China. JAMA. 2020;323:1061-9.

8. Thygesen $\mathrm{K}$, et al. Fourth universal definition of myocardial infarction (2018). Glob Heart. 2018;13(4):305-38. https://doi.org/10.1016/j.gheart. 2018.08.004.

9. Metkus TS, Sokoll LJ, Barth AS, Czarny MJ, Hays AG, Lowenstein CJ, Michos ED, Nolley EP, Post WS, Resar JR, Thiemann DR, Trost JC, Hasan RK. Myocardial injury in severe COVID-19 compared with non-COVID-19 acute respiratory distress syndrome. Circulation. 2021;143(6):553-65. https:// doi.org/10.1161/CIRCULATIONAHA.120.050543.

10. Lala A, Johnson KW, Januzzi JL, Russak AJ, Paranjpe I, Richter F, Zhao S, Somani S, Van VleckT, Vaid A, Chaudhry F, De Freitas JK, Fayad ZA, Pinney SP, Levin M, Charney A, Bagiella E, Narula J, Glicksberg BS, Nadkarni G, Mancini DM, Fuster V, Mount Sinai COVID Informatics Center. Prevalence and impact of myocardial injury in patients hospitalized with COVID-19 infection. J Am Coll Cardiol. 2020;76(5):533-46. https://doi.org/10.1016/j. jacc.2020.06.007.

11 Majure DT, Gruberg L, Saba SG, Kvasnovsky C, Hirsch JS, Jauhar R, Northwell Health COVID-19 Research Consortium. Usefulness of elevated troponin to predict death in patients with COVID-19 and myocardial injury. Am J Cardiol. 2021;1(138):100-6. https://doi.org/10.1016/j.amjcard. 2020.09.060.

12. Case BC, Yerasi C, Forrestal BJ, Shea C, Rappaport H, Medranda GA, Zhang C, Abramowitz J, Satler LF, Ben-Dor I, Hashim H, Rogers T, Waksman R. Clinical impact and predictors of troponin elevation in patients with COVID-19. Cardiovasc Revasc Med. 2021. https://doi.org/10.1016/j.carrev. 2021.03.002.

13. De Michieli L, Ola O, Knott JD, Akula A, Mehta RA, Hodge DO, Dworak M, Yang EH, Gharacholou M, Singh G, Singh R, Gulati R, Jaffe AS, Sandoval Y. High-sensitivity cardiac troponin $t$ for the detection of myocardial injury and risk stratification in COVID-19. Clin Chem. 2021. https://doi.org/10. 1093/clinchem/hvab062.

14. Pachtman Shetty SL, Meirowitz N, Blitz MJ, Gadomski T, Weinberg CR. Myocardial injury associated with coronavirus disease 2019 in pregnancy. Am J Obstet Gynecol. 2021;224(2):229-32. https://doi.org/10.1016/j.ajog. 2020.10.014.

15. Shi S, Qin M, Shen B, et al. Association of cardiac injury with mortality in hospitalized patients with COVID-19 in Wuhan, China. JAMA Cardiol. 2020;5:802.

16. Guo T, Fan Y, Chen M, et al. Cardiovascular implications of fatal outcomes of patients with coronavirus disease 2019 (COVID-19). JAMA Cardiol. 2020;5:811.

17. Zhou F, Yu T, Du R, et al. Clinical course and risk factors for mortality of adult inpatients with COVID-19 in Wuhan, China: a retrospective cohort study. Lancet. 2020;395:1054-62.

18. Chen T, Wu D, Chen H, et al. Clinical characteristics of 113 deceased patients with coronavirus disease 2019: retrospective study. BMJ. 2020;368:m1091.

19. Nuzzi V, et al. The prognostic value of serial troponin measurements in patients admitted for COVID-19. ESC Heart Fail. 2021;8(5):3504-11. https://doi.org/10.1002/ehf2.13462.

20. Barton LM, Duval EJ, Stroberg E, Ghosh S, Mukhopadhyay S. COVID-19 autopsies, Oklahoma, USA. Am J Clin Pathol. 2020;153:725-33.

21. Zheng YY, Ma YT, Zhang JY, Xie X. COVID-19 and the cardiovascular system. Nat Rev Cardiol. 2020;17:259-60.

22. Xiong TY, Redwood S, Prendergast B, Chen M. Coronaviruses and the cardiovascular system: acute and long-term implications. Eur Heart J. 2020:41:1798-800.

23. Magesh S, John D, Li WT, Li Y, Mattingly-App A, Jain S, Chang EY, Ongkeko WM. Disparities in COVID-19 outcomes by race, ethnicity, and socioeconomic status: a systematic-review and meta-analysis. JAMA Netw Open. 2021;4(11):e2134147. https://doi.org/10.1001/jamanetworkopen.2021. 34147.

\section{Publisher's Note}

Springer Nature remains neutral with regard to jurisdictional claims in published maps and institutional affiliations.

Ready to submit your research? Choose BMC and benefit from:

- fast, convenient online submission

- thorough peer review by experienced researchers in your field

- rapid publication on acceptance

- support for research data, including large and complex data types

- gold Open Access which fosters wider collaboration and increased citations

- maximum visibility for your research: over 100M website views per year

At BMC, research is always in progress.

Learn more biomedcentral.com/submissions 